\title{
Institutional Matchmakers, Sponsors, and Strategists: Roles of Academic STEM Executives in Developing the Next Generation of Leaders
}

\author{
Diane M. Magrane1, Page S. Morahan'1, Susan Ambrose², Sharon A. Dannels ${ }^{3}$ \\ ${ }^{1}$ Institute for Women's Health and Leadership, Drexel University College of Medicine, Philadelphia, PA, USA \\ ${ }^{2}$ Office of the Provost, Northeastern University, Boston, MA, USA \\ ${ }^{3}$ Department of Educational Research, George Washington University, Washington DC, USA \\ Email: dmm347@drexel.edu
}

How to cite this paper: Magrane, D. M., Morahan, P. S., Ambrose, S., \& Dannels, S. A. (2018). Institutional Matchmakers, Sponsors, and Strategists: Roles of Academic STEM Executives in Developing the Next Generation of Leaders. Open Journal of Leadership, 7, 168-186.

https://doi.org/10.4236/ojl.2018.72010

Received: April 24, 2018

Accepted: June 23, 2018

Published: June 26, 2018

Copyright $\odot 2018$ by authors and Scientific Research Publishing Inc. This work is licensed under the Creative Commons Attribution International License (CC BY 4.0).

http://creativecommons.org/licenses/by/4.0/

\begin{abstract}
Current literature shows a growing consensus about the importance of talent development of diverse leaders; however, less information is available about how this is accomplished within higher education and how these goals might be advanced or hindered by current practices. Interviews with 32 STEM (science, technology, engineering, and math) academic leaders, most from engineering and computing sciences, provided information about how these leaders identify, select, develop, and support emerging leaders in their organizations. Interviews were coded specifically for mentoring and sponsorship practices. Coding of individual de-identified transcripts described general themes; poetic transcriptions created collective narratives to elaborate perspectives and practices across the themes. The leaders described three interdependent roles: 1) Matchmakers who watch for talent to "bubble up" and aim to determine "fit" of new positions to individual talents and optimal career timing; 2) Mentors and Sponsors who counsel and advocate to advance the careers of others; and 3) Institutional Strategists whose support of new leaders aims to minimize risk and achieve organizational goals. The practices described have both a future orientation and a potential for inhibiting diverse leadership development as a result of implicit bias in supporting academic status quo. Knowledge of these approaches is useful to aspiring and newly appointed leaders. Also, organizational leaders can use this information for more comprehensive talent development that creates a deeper talent pool for leaders across higher education.
\end{abstract}

\section{Keywords}

Talent Management, Sponsorship, Inclusive Faculty Development, Academic STEM Leaders, Implicit Bias 


\section{Introduction}

Accelerations in scale and pace of change in technology and globalization call for nimble leadership and career-aligned learning systems that can respond to both institutional and community needs (Barber, Donnelly, \& Rizvi, 2013; Friedman, 2016). Academia has been slow to adopt one of the best attributes of business culture: "its tradition of developing leadership through succession planning" (Blumenstyk, 2005: p. A28). This resistance to organizational succession development in higher education arises from: 1) insufficient investment in human resource management; 2) lack of cross-organization transparency to address the tension of shared governance between faculty and the executive decision-making; and 3) a culture that looks for internal appointments from outside the organization, often drawing from a network that results in candidates that mirror the existing power network of white men with traditional paths of scholarship (American Council on Education, 2017; Bridges, Eckel, Cordova, \& White, 2008; Korn Ferry Institute, 2015; Rothwell, 2005).

In North America, national efforts to enrich the diversity of higher education leadership pools focus largely on programming (American Council on Education, 2018; Harvard Institute for Educational Management, 2018). The National Science Foundation ADVANCE programs (DeZure et al., 2014), HERS Institute (White, 2012), and Drexel University ELAM ${ }^{\star}$ (Morahan, Gleason, Richman, Dannels, \& McDade 2010) and ELATE ${ }^{\circledR}$ (Magrane \& Morahan, 2016) programs address the paucity of women in STEM academic leadership in particular. Less often recognized is the important influence of sponsors who support advancement of protégés using their organizational clout and reputation (Foust-Cummings, Dinolfo, \& Kohler, 2011; Hewlett, Peraino, Sherbin, \& Sumberg, 2011). Although not extensively studied in higher education, sponsorship practices are being recommended for advancing women into STEM leadership (DeZure et al., 2014; Travis, 2013) and to advance NIH funded research (Patton et al., 2017). For almost two decades, scholars of academic leadership development have been calling for new processes of talent management that identify, inspire, and prepare diverse faculty for administrative leadership roles (Betts et al., 2009; Clunies, 2004; Gigliotti \& Ruben, 2017; Gmelch, 2000; Gonzalez, 2010). Many of these recommendations are similar for corporate, military, and academic organizations (Gmelch, 2017; Hoehn et al., 2011; Rayburn et al., 2016). They involve organization-wide mentoring and professional development, performance assessment linked to individual aspirations and organizational mission, and internal sponsorship of emerging leaders for leadership "stretch" experiences.

\section{Purpose of the Study}

This qualitative study was designed to explore how an important and under-studied group, sitting academic leaders from STEM fields, address the crucial need to identify, recruit, develop, and retain diverse talent in academia. In 
considering the over-arching research question: how do academic STEM leaders describe their roles in developing the next generation of leaders in STEM? the study probes: 1) the language that leaders used to describe actions of talent management and 2) specifically how they describe sponsorship within their academic environments.

\section{Methodology}

Using a critical theory paradigm, this interpretive qualitative study presents analyses of confidential interviews from established academic leaders with backgrounds in science and engineering. Qualitative content analysis of de-identified transcripts included both manifest analysis of direct responses to the questions and a deeper latent analysis of what was said (and not said) relevant to research and published practices on development of emerging leaders (Bengtsson, 2016). The research was conducted by a team of researchers with the approval of Drexel University's IRB.

\subsection{Participant Selection and Interview Protocol}

The initial group of interview participants was purposively selected based upon their academic leadership position, STEM background, and their participation with ELATE, so as to study those most likely to be actively developing individuals from diverse backgrounds for leadership. Snowball sampling was then used to identify additional academic leaders from STEM fields. A total of 44 leaders were contacted to request participation; 32 responded to the invitation and were interviewed before saturation was achieved. Of those interviewed 16 were deans and 16 were provosts, chancellors, or presidents-all but three from engineering and computing sciences. The final sample was predominately composed of individuals with knowledge of ELATE as Advisory Board members, program facilitators, or sponsors of ELATE Fellows.

Items in the interview protocol (available upon request from the authors) were informed by the literature on mentoring and sponsorship and the semi-structured protocol was pilot tested prior to use. Each confidential telephone interview was completed within 30 - 49 minutes and all interviews were conducted over a four-month period by the same individual. With permission, all interviews were audio recorded. Interviews were transcribed verbatim and identifying information was redacted prior to analysis. After the first ten interviews, analysis was concurrent with ongoing data collection and no changes were made in the protocol.

\subsection{Analysis of Interview Data}

Three members of the research team initially topic coded data into five categories aligned with the five organizing questions in the interview guide; in an iterative process, two additional team members further coded data within each category and then across categories to identify themes. Indigenous or in vivo codes 
were used to identify themes in the language of interview participants where possible. Contributors provided permission to use direct quotes as presented in this publication, which each identified by a unique number without other identifying information.

Three overarching leadership perspectives were identified by an iterative consensus process. Each theme is elaborated in the Discussion section along with a poetic transcription of the data (Glesne, 1997). Words and phrases of individual contributors from all transcriptions (not limited to the quotes presented in the Findings) were used to create a poetic transcription for each of the dominant themes, without introducing any new terms from the authors. This method of qualitative analysis elaborates the qualities of each theme by reinforcing predominant thoughts and amplifying novel ideas that may not be captured with the primary thematic analysis; in addition, it provides a check on the congruence of themes with the collective voice of the STEM leaders (Cahnemann, 2003; Edwards \& Weller, 2012; Glesne, 1997).

\section{Findings}

Whereas some academic executives described identification of leaders as serendipitous, most described a more intentional approach to identifying, developing, and supporting faculty leaders (Table 1).

\subsection{Scanning for Talent}

In responding to the opening interview question, "What do you do to identify

Table 1. Interview themes: how do STEM academic administrators identify and develop leaders?

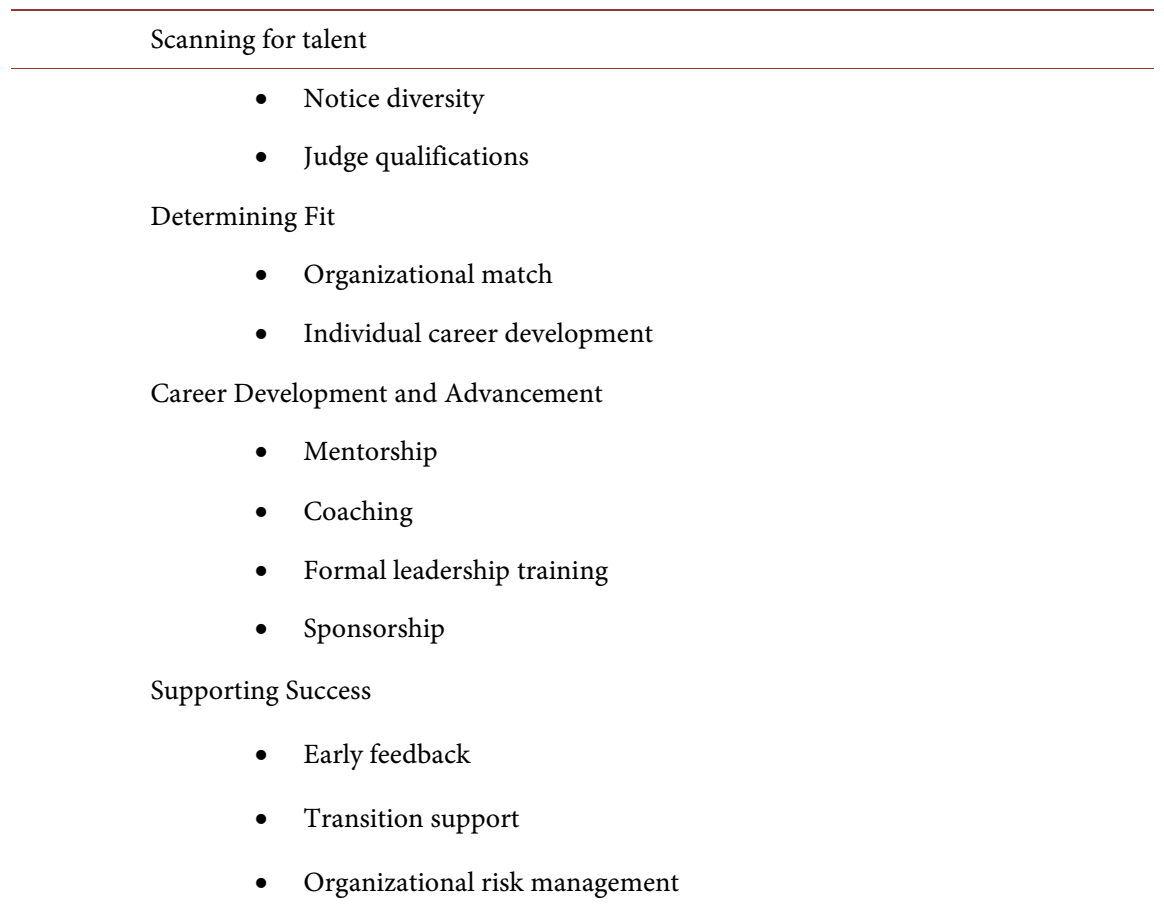


potential leaders?" nearly every respondent described constant surveillance for actions, interactions, and referrals that bring potential leaders into their awareness (e.g., always keeping an ear to the ground). Recognizing their professional distance from emerging leaders, they often relied upon trusted colleagues to identify potential talent. Although diminishing the importance of formal letters of recommendation from outside their network, several emphasized referrals from trusted acquaintances.

Surveillance for potential occurred in a variety of settings-professional development workshops, committee meetings, and social events. The leaders described how they position themselves to see faculty leadership bubbling up and stepping up through participation in campus leadership activities and direct applications for open positions. "There are opportunities to hear faculty leadership emerge typically in faculty retreats for strategic planning or charrettes focused around a particular issue or priority for the school. That's a natural way to see leadership potential bubble up" ( $\$ 21$ ). Several described following up on new connections with additional conversations to explore interest and/or potential, or sometimes just planting the seed.

Noticing diversity. Leaders also described expanding the potential pool for diverse faculty leaders, especially those who are underrepresented by race, ethnicity, and gender. Several addressed the search process, one monitored the promotion list for women. Another interviewee described seeking such faculty early in the process: "I emphasized diversity of candidates and to look in places most normally would not. ... I wanted the search committee to look everywhere to find viable candidates and to not search for people like us" (\#19).

Judging qualifications. Responses to the introductory question, "What important skills do you look for?" almost always opened with a description of personal characteristics and abilities accompanying proven academic credibility. This baseline was clearly viewed as having earned a strong reputation, and proven track record as a respected scholar.

We start from the fact that they have to be very well respected for their academic endeavors. It is difficult in this environment to be an effective leader if you don't have a level of credibility which is based upon what you have accomplished academically. (\#28)

Only one extended this to include how that path to scholarship demonstrates specific leadership skills:

In academia, have they been able to create and grow a viable research program that's sustained over many years, as that requires a certain level of visioning, collaboration, and communication with colleagues at the faculty level, graduate students, and undergraduate students. The ability to have a successful academic program requires not just good scientific ideas or being able to write a grant and deliver on that grant but also to be able to grow the program so that colleagues and others involved develop those skills. (\#26)

Despite the interview question asking about requisite leadership skills, the responses predominately focused on personal characteristics and attributes. 
These included integrity, responsibility, and discretion that gives definition to trustworthiness; humility, a tough skin, and self-awareness that establishes a sense of equanimity; and being able to inspire others to change as being aspirational oneself.

Later in the interviews, after discussing personal characteristics and academic credibility, the leaders described seeking a more complex set of organizational change and decision-making skills, taking special note of effectiveness in collaboration, persuasive communication, and execution of responsibilities. One leader phrased the criteria as those "who have the ability to work with other people, have the communication skill to inspire people, and energy to take action" (\#10). Collaboration was described as an action of inclusion, consensus-building, and delegation of responsibility exhibited by nurturing diverse individuals who bring out the best in others, exude confidence in others' abilities, and create a climate of mutual respect. "They are hard workers, team players, faculty around them listen to them" (\#17). Communication skills were described as extending across verbal, nonverbal, and written information, and through both expression and attentive listening. Execution was described in terms of resourcefulness and achievement, seeking those who can "take ownership of an activity and to do whatever it takes to get that task done as opposed to giving excuses. I look for who is not complaining, who is using the resources that they have"(\#4).

Several described more sophisticated approaches to leadership. These as strategic, integrative, critical, and creative. Leaders reported the ability to extend thinking beyond one's own field or discipline (i.e., to see the big picture) and place the larger organization first in processes of information gathering, decision making, and leading change as ideal. "I like what Debra Meyerson calls 'tempered radicals. They can't want to blow the boat up; they should want to rock the boat and stay in it. Those are important qualities I look for" (\#13).

\subsection{Determining Fit}

Organizational match. When the opportunity arose to support a faculty member for a leadership position, the concept of fit took on critical importance. Fit was described in two ways: first, as a match between the individual's abilities and experiences with a proposed organizational role, and second, as a within-person determinant in terms of the timing and trajectory of a professional career.

In considering the match of individuals to positions, interviewees considered how the potential leader would complement others with whom he/she would most closely work.

I do a lot of research on the position to try to do a kind of matching... based on what I know about the person and what the position entails. It doesn't mean one person is better than another but it's just that some are better suited for the position based on where they are in their career. (\#23) 
Executive leaders talked about considering candidates from previous searches because they frequently saw applicants who were exceptionally good but not a fit for the position being searched.

Individual career development phase. Within the context of protégés' career development, leaders described making judgements about fit of timing and suitability of work:

So sometimes it's a matter of fit...matching aspects to consider diversity of teams, intellectual diversity, and right time in career for that person... Or the more difficult case where someone could be a leader, has all the skills and then you debate if they would be happier doing this or being a highly successful faculty member. Are they better suited being a leader through research and teaching than being a leader through administration? ... Are you doing them any favors to ask them to be in this role? So part of the process is trying to figure out would they really thrive as a human being as well a leader. (\#21)

\subsection{Career Development and Advancement}

When asked, "What do you do to advance a leader?", the executive STEM leaders described different approaches to mentoring, coaching, and sponsorship. For both potential and newly appointed leaders, the importance of continuing conversation was important in the development of talent.

Mentorship. Many of the STEM leaders described mentoring relationships in which they nurtured, empowered, and advised protégés according to the protégés career development stage. Several specifically identified this as a mentoring relationship and emphasized pushing the individual to broaden his/her academic scope and expand his/ her professional network while protecting from distractions because "everyone wants a part of them" (\#15).

Coaching. They variously described their roles in the relationship as to groom, cultivate, and coach as they helped the protégé understand the environment, appreciate that she/he has leadership potential, and to prepare for future possibilities. "We talk through current issues the university is facing and how she would deal with them. I am trying to make her think more globally" (\#14). Some bounded their role as a resource-someone to guide the protégé's reflection. "I never tell them what to do. Mentors can sometimes be tormentors. I see the potential and try to do my best in terms of opportunities and connections" (\#15). Others took a more directive approach, taking advantage of teachable moments to coach around deficiencies, being clear about what is working and what is not.

Formal leadership training. Formal training was discussed in terms of extended programs, skill-building workshops, and individual coaching. As one leader explained, "In academia, leadership is a skill that we need to develop like we can develop a skill in the lab... leadership then becomes a new dimension of their research program and academic portfolio" (\#26). Some leaders reported using training sessions to assess leadership gaps and strengths, for example: "We train people to be mediators because through this training, we learn more about 
the individual s skill set and attitudes" (\#13).

Sponsorship into new leader roles. When asked "What do you do to advance someone into a leadership position?", respondents moved the conversations from mentorship to actions of sponsorship, both directly by making important connections to influential individuals and to early leadership positions and actions behind the scenes. One leader, who reported having numerous faculty on the radar for leadership opportunities, noted how she looks "at ways to connect them within the academic community. I position them to have influence in ways that they would not otherwise"(\#30). Several described creating smaller leadership positions to develop skills and then gradually increasing responsibility. "We are doing our best to give her the experience and opportunities to grow into [a] senior level position" (\#14). The mandate of don't micromanage was frequently repeated; and the importance of letting her/him fail was also noted along with the admonition, but be there to support. "These people have character and learn to be humble because you let them try, explore, and sometimes fail. You are always there to hold them up if they fall' (\#15).

Leaders very clearly described the reciprocity inherent in a sponsorship-protégé relationship. This was evident in the sense of personal responsibility for nominating a protégé: "formally signing a name to a document saying this person is qualified for the position... [is] taking a lot of risks by putting my name in an external hiring process" (\#23). They acknowledged the shared risk and achievement as "other people are watching and they see that you are helping that person succeed" (\#3). As one leader noted, "I let them know that their success is my success so I will always do what I can, however, I expect reciprocity" (\#19).

Support for advancement might focus on a position for which the leader had control or for a position outside of the leader's direct influence. Descriptions of behind-the-scenes advocacy arose when addressing successful recruitment efforts and preparation for new leader roles. One leader spoke at length of working with a group of stakeholders to appreciate why the protégé might be the right leader for them:

In the end they have a clear understanding of what they should be thinking about who they would like as a leader. So they think that person would be good and people feel that it is done through a consensus building process. So people feel they have meaningful input and now they are excited about the possibility and it sets the person up for success. (\#3)

Occasionally, the behind-the-scenes work to advocate for the nomination came before the direct conversation with the protégé:

I didn't talk to him first because ...I wanted there to be some level of surprise in their regard that someone else thought so highly of them and their skills. So it was surprising to them. It's so easy to say "no" when they don't see it in themselves but I wanted them to know what others thought of them before they did. (\#26)

However, they also acknowledged the potential downside of too much interference in the selection process. "Maybe it is because I may have thrown 
some hints but I do not meddle in the process. Based on my experiences, administrators who meddle in the process create trust issues" (\#37). Yet another emphasized how important it was to work with search committees to make their own recommendations rather than using the positional authority of the leader:

... if the recommendation is against the person, then you are not doing anyone any favors getting them off to a bad start. So there is actually a lot of consensus building behind the scenes that the person you want is the same as the person who the larger group of people want. It is a hard system to understand but the system works well because then the individual gets off to a great start. They have support of their superior, the faculty, and other larger group of people from the committee. (\#23)

With new leaders, one function of sponsorship that emerged from the interviews was the responsibility to provide the resources necessary to be successful. These arrangements sometimes occurred behind the scenes and sometimes in the course of negotiations for financial resources, people, and/or the time and space to take on the new responsibility. In preparing appointees for new leadership roles, some discussed adjusting staffing and workload to increase the likelihood of early success:

I talked to people [other faculty] and encouraged them to take on part of the administrative load. If he was going to be successful, he would need some help and I worked behind the scenes to do that. (\#4)

Executive leaders specifically cited surrounding the protégé with the right team and encouraging success through team building.

\subsection{Supporting Success in a New Position}

In responding to the question, "What do you do to support a leader after achieving a new position?", the executive leaders described developmental approaches with early feedback, transition support, and risk management.

Developmental approaches and early feedback. They reported using formal and informal sessions to clarify expectations and set goals that supported organizational goals and the mentor's vision. Over time these meetings were used to provide feedback-informally as well as via performance management systems or annual reviews. In addition, team meetings were described as useful for team building, providing a greater perspective, and enlarging the new leader's network.

Transition support. Publicly supporting the individual was cited as a means by which the leader used his/her capital to aid the ascension of the protégé. For some they clarified that this was done even if they did not agree with a decision.

One thing I do not do publicly is toss someone under the bus. I will never publicly not support the person. It's also about communication. You need to have a comfortable position with someone behind closed doors-tell someone why you think they are wrong. You may not agree all the time but whatever the 
conclusion is, they have my full public support. (\#14)

One leader remarked on how critical it was to explicitly express support for underrepresented faculty in leadership roles,

The main thing that I did was to talk to her and reassure her that she was going to have the support of the faculty and of the Deans if she was going to do the job properly. That is an important thing for women in male dominated fields and with underrepresented minorities. All leaders fear that they might not have support of their superiors and worry about being undermined by those in charge. That fear can be greater on the part of women and for underrepresented minorities. (\#25)

Transition support also included honoring the individual for who he/she is and trusting the leadership attributes that originally captured the executive leader's attention and not micromanaging. "You set priorities and you coach people through the process of leading and you set a tone where we are in it together and your success is my success" (\#3).

Managing organizational risk. The STEM leaders were consistent in describing their dual investment-in the success of protégés as well as their sense of responsibility to the university. When asked "What do you do when there is a problem with the new leader?", almost all described the importance of stepping in at the first sign of trouble with conversations and actions that matched the seriousness of each situation. They described coaching around the deficiencies, collaborating to find solutions, and sometimes, managing the situation themselves. The immediacy of the response was related to an acknowledgement that in addition to shared success, "their failure is your failure" (\#21).

These institutional leaders described managing difficult situations with new leaders in the context of the boundaries of protecting the organization from risk. Frequently they mentioned seeking the advice of the university attorneys as well as their trusted colleagues. They described as thoughtful deliberations about how to manage the environment and the individual. One noted: You need to go back and think about what went wrong and make some mid-course corrections. In academia, sometimes things can get over exaggerated. ... we need to assess the situation and make some mid-course corrections. The main thing is not to overreact. (\#23) As much as possible, they worked to maintain support and dignity for the new leader at risk. Those efforts were not always successful. In the experience of one leader:

You try to rescue, educate, set goals, and give feedback. But at a certain point you have to be realistic about it and realize that if it is getting in the way of the organization and you cannot think of another way to remediate, there are times when you have to cut the connection. (\#24)

In cases where the solution was separation, leaders worked creatively to find a dignified exit or transition to a new role, noting that not doing so could damage both the protégé and the institution in recruiting the successor. "If it is time for a change, then you make the change" (\#3). 


\section{Discussion: Succession Strategies}

These interviews both support findings from other studies of leadership talent development and add new insight into how STEM academic executives think about identifying, developing, supporting and managing emerging leadership. These insights are valuable in both practice and research — to faculty interested in pathways to leadership, managers of talent development across university and college campuses, and to scholars of academic leadership.

The results highlight an important dilemma in higher education leadership succession: How can individual leaders, most of whom are advantaged by race, gender, and economic standing, negotiate their respect for transparency and shared governance with advocacy for talent with diverse backgrounds? How do they hold their footing in the traditions of academia while encouraging innovation? Their collective narratives, presented as poetic transcriptions of the interviews in compositions of the words and phrases used by a wide range of leaders, address these dilemmas in terms of three interdependent roles as organizational matchmakers, mentors and sponsors, and institutional strategists (Table 2).

\subsection{Organizational Matchmaker}

In this role, leaders utilized their networks and a variety of interactions to take notice of individuals with talent and interest in leadership. The poetic transcription, Matchmaker, reveals a sense of responsibility for identifying potential and an awareness of the importance of attending to equity in building diverse teams.

\section{Matchmaker}

I have an ear to the ground

for potential leaders,

for folks to help build my bench.

I listen for names that come up often,

Search into places most normally would not-

Training programs, retreats, charettes, discussions-

Constantly watching people in action,

Watching for leadership potential to bubble up.

I have 20 faculty on my radar-

Men who say "I am the right candidate?"

Women who haven't yet realized that leadership is their future

Hispanics, African Americans, Asian Americans

looking for ways to exert their leadership,

Underrepresented and worth waiting for.

I do a kind of matching

For the right diversity, the right role

For the team and for their career to thrive.

It's a matter of fit:

How are they able to create, collaborate, and

communicate to colleagues? 
Table 2. Succession strategies: Roles of academic STEM administrative leaders.

\section{Organizational Matchmakers identifying and "fitting" faculty}

to leadership roles as they are opened or created

1) Constant surveillance for potential by

a) Participation in campus events

b) Conversations with colleagues

c) Taking note of people who "bubble up" in conversations about

leadership and "step up" to smaller leadership activities

d) Considering recommendations of colleagues

e) Attention to search committee processes

2) Noticing diversity of background, experience and thought

3) Judging qualifications with regard to

a) Credibility in scholarly work

b) Characteristics of personality and work style

c) Collaboration with diverse team members

d) Communication across various modes

e) Organizational thinking that considers institutional needs

4) Determining "fit"

a) Matching characteristics, abilities, and experience to open opportunities

b) Assessing timing for the individual within his/ her career trajectory

Mentors advising and supporting and Sponsors leveraging their positions to advance emerging leaders

1) Mentorship: identifying goals, broadening scope of work and expanding networks; protection from overcommittment

2) Coaching: talking through pending and hypothetical situations, providing feedback, setting goals and expectations

3) Formal leadership training for skill development

4) Sponsorship into new roles:

a) Assigning/ nominating to positions that increase influence, visibility, and responsibility

b) Advocating for selection through positive and un-pressured input to search committees

c) Advocating for early success through conversations with colleagues in the unit that leader is joining.

d) Providing transition support of resources and mentoring

e) Acknowledging support publicly, admonishing and correcting privately

Institutional Strategist advancing organizational goals, minimizing risk to reputations (university, protégé, and self), ensuring stability of institutional operations

1) Supervising and conducting performance evaluations:

a) Setting goals and providing resources

b) Stepping in early with feedback appropriate to degree of error/ challenge

2) Collaborating when possible; managing when necessary; separating if no other option

3) Managing risk:

a) Protecting institution from fiscal/ legal risk;

b) Protecting individuals from reputational risk 
I ask, "am I doing them a favor to be nominated?"

"Would they be happier being a leader through research and teaching

Or through administration?"

It's part of my job as a leader:

Ear to the ground,

Constantly watching

Matching for fit

Building support

Building my bench.

The Matchmaker narrative highlights the active role of constant surveillance and assessment of talent as executives acknowledged current and future organizational needs to build and sustain strong leadership teams. Despite acknowledging the need to consider gender and race, most of leaders' approaches to noticing prospects were generalized across all faculty. By relying upon agentic behaviors of stepping up through volunteerism and bubbling up through external nominations, their surveillance introduces the potential for implicit bias that may omit women and minorities (Fletcher, 2001). Research on the impact of agentic behaviors suggests that such behaviors may lie outside their cultural training (Markus \& Conner 2013), that women are less likely to self-promote than men (Carnes, Geller, Fine, Sheridan, \& Handelsman 2005), and that white women and black men may be judged harshly for strongly agentic actions (Livingston, Rosette, \& Washington 2012). On the other hand, the communal nature of the work in professional development activities and collaborative projects across campus may add advantage to women and minority men when "the matchmakers" take notice of their individual contributions.

This poetic transcription also highlights the view of "fit" as a duality of organizational match for need and individual match for characteristics and career timing. Interviews indicated these as an intuitive matching of each person with potential leadership roles and the existing academic culture. Research, however, points to the hazards of relying upon intuitive sense of matching as a barrier to expanding diversity (Chamorro-Premuzic \& Murphy, 2017; Korn Ferry, 2018) and a promoter of "status quo" bias-a dependence upon doing things the way they have always been done-in which actions with the best of intentions result in negative consequences (Ross, 2014). Doors to leadership are most likely to open when organizations match explicit qualifications for positions and efforts (Carnes \& Bland, 2007) and develop faculty along a progression of leadership positions and skills (Morahan, Rosen, Richman, \& Gleason 2011). In their unique roles as institutional leaders and mentors to developing leaders they are in a position to move beyond intuitive fit to a more comprehensive cross-organizational approach to talent management.

\subsection{Mentors and Sponsors}

The list of sponsorship activities in the poetic transcription, Shared Success, mirrors that of corporate sponsorship (Hewlett, Marshall, \& Sherbin, 2011). 
More importantly, the collective narrative reveals the tensions of holding dual responsibility as advocates and coaches for protégés and as stewards for the institution. It brings out a deep sense of shared responsibility for serving the institution.

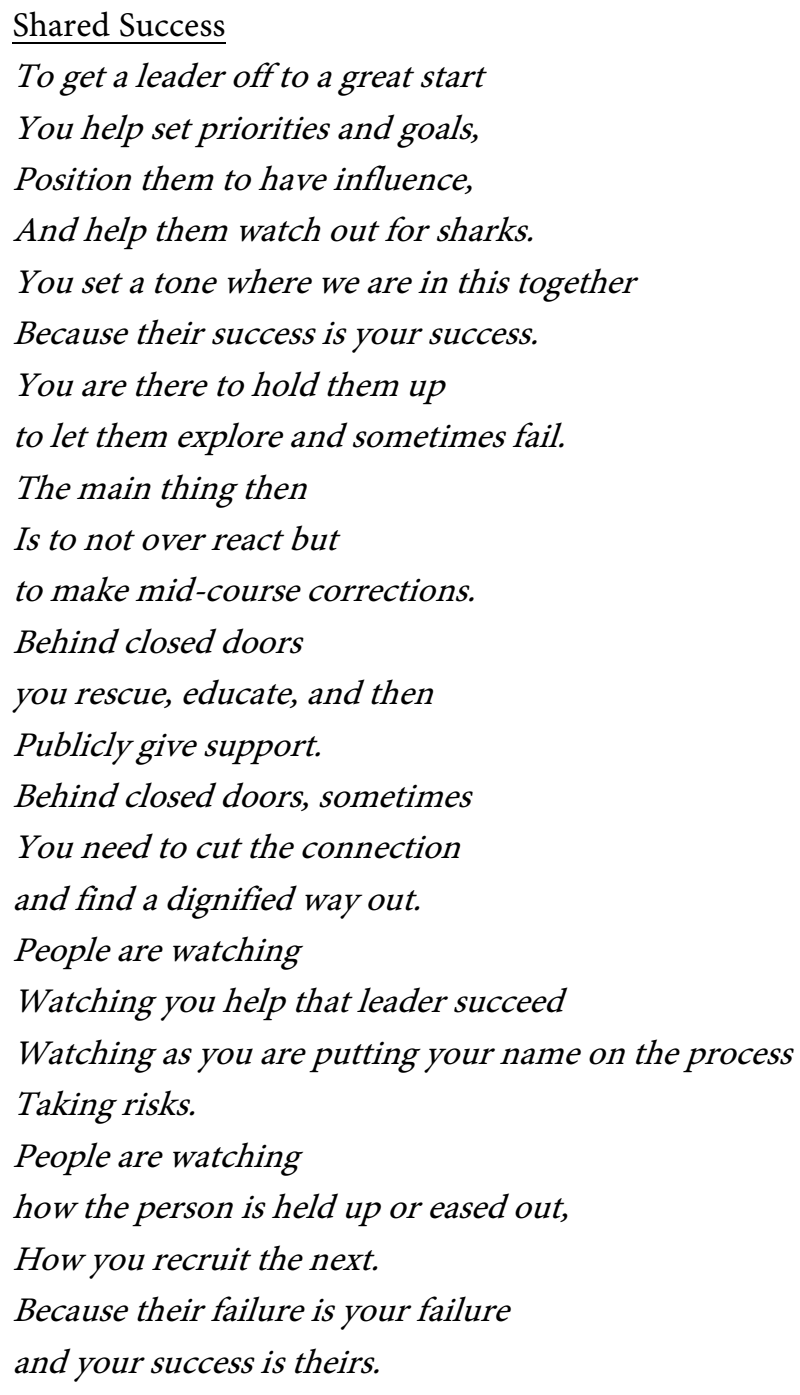

This poetic transcription gives guidance in how to carry out sponsorship in academic settings. As noted in corporate sponsorship relationships (Hewlett, Marshall, \& Sherbin, 2011), leaders expressed an expectation of shared risk and shared success; they also portrayed a definite pattern of advocacy that is described as behind the scenes preparation and behind closed doors correction.

\subsection{Institutional Strategists}

The poetic transcription, Academia, uses words that are persuasive, political, and respectful of the traditions of shared governance of the academy. It describes multiple levels of responsibility to new leaders and to the institution as a whole.

Academia

In academia

Leadership is a new dimension of skill to develop, 
Adding to the portfolio of research and teaching.

But the system of getting leaders off to a great start

can be hard to understand.

Administrators

Lobby behind the scenes

Building consensus;

Not top down and

Never meddling in a process that works

That creates trust issues.

(But I may have thrown some hints.)

In difficult situations

Things can get over exaggerated

You have to not over react.

But when the leadership issues are getting in the way of the organization

You have to take ownership, be realistic

and it takes some real creativity

To do what it takes.

The role of the leader involves as a more careful negotiating behind the scenes than typical in a corporate environment-careful not to "meddle", cautious about over-reacting, advocating for new leaders "behind the scenes", and admonishing "behind closed doors". The role of institutional strategist showed most poignantly in discussions of what to do when the newly chosen leader makes poor decisions. Working through phases of development, correction, and separation with dignity, they maintain their responsibility to institutional integrity.

\subsection{Study Limitations}

The primary limitation in this study is in the specific focus of the sample interviewees, primarily from engineering or computing fields, and almost all involved with ELATE. First, although they provided a unique perspective as STEM leaders, there may be cultural influences in protégé advancement that differ from social sciences or humanities. Second, as executive academic leaders, the role they play in identification and development of potential leaders may differ from the role of department chairs and associate deans who have less distance from the general faculty. The interview questions did not distinguish whether processes are the same when considering recruitment of a committee member, department chair or provost. Finally, the sample's involvement with ELATE may suggest a heightened awareness of the importance of leadership development of women. However, the interviews showed that considerations of diversity focused largely on recruitment and was less on the minds of leaders when describing support after leadership appointment.

\section{Conclusion}

These academic executive leaders' descriptions of their roles in developing the 
next generation of leaders provide insights into current practices, and also highlight opportunities to build an even more diverse work force of academic leaders in STEM. Three dualities are evident; these academic leaders seek to: 1) support diverse individuals, while utilizing processes that support the status quo of academia; 2), advocate through sponsorship, while respecting decision-making of shared governance; and 3) coach for success, while monitoring for risk. Inherent in the STEM leaders' processes were limitations of infrastructure for faculty development and implicit bias that carries the potential to counter the goals of supporting local talent and developing diverse work forces on campus.

The findings in this study of STEM based leaders also apply across the continuum of leadership development in higher education. Young faculty who aspire to leadership need to take actions that make their contributions visible to leaders across campus, while also building academic credibility and a reputation of effective collaboration (Morahan, Rosen, Richman, \& Gleason 2011). Learning to "speak up" and to "step up" professionally is more likely to set them on a track of sponsored leadership than waiting for invitations. Newly appointed leaders would benefit from the role modeling of these effective STEM leaders, evident in the direct and collective transcriptions.

A cohort of leaders represented in these interviews have demonstrated sponsorship for aspiring academic leaders through their roles as mentors, coaches, and sponsors once their protégés landed in a leadership position. But how many current academic leaders support potential future leaders in such a holistic way? And how many do so without an infrastructure of talent development that supports talent development from early contributors to campus activities to organizational executive? In the end, a systems approach of professional development and organizational accountability for leadership competencies that includes talent management provides the best infrastructure to support the conscientious intentions of our leaders.

\section{Acknowledgements}

The authors would like to acknowledge the contributions of Brenda Seals $\mathrm{PhD}$ in conducting the initial interviews, Wenting Luo MPH and Ekta Panjrolia for preparing transcripts and assistance with coding, and Nily $\mathrm{Dan} \mathrm{PhD}$ for assisting with validation of interview questions. This work was supported in part by a grant from the Alfred P. Sloan Foundation Grant \#2012-12-03.

\section{References}

American Council on Education (ACE) Fellows Program (2018). http://www.acenet.edu/leadership/programs/Pages/ACE-Fellows-Program.aspx

American Council on Education, American College President Study 2017 (2017). http://www.acenet.edu/news-room/Pages/American-College-President-Study.aspx

Barber, M., Donnelly, K., \& Rizvi, S. (2013). An Avalanche Is Coming, Higher Education and the Revolution Ahead. London: Institute for Public Policy Research.

Bengtsson, M. (2016). How to Plan and Perform a Qualitative Study Using Content 
Analysis. Nursing Plus Open, 2, 8-14. https://doi.org/10.1016/j.npls.2016.01.001

Betts, K., Urias, D., \& Betts, K. (2009). Higher Education and Shifting US Demographics: Need for Visible Administrative Paths, Professional Development, Succession Planning and Commitment to Diversity. Academic Leadership Journal, 7, No. 2. http://scholars.fhsu.edu/alj/vol7/iss2/6

Blumenstyk, G. (2005). Outside Chance for Insiders. The Chronicle of Higher Education, 52, A28-A29. https://www.chronicle.com/article/Outside-Chance-for-Insiders/23524

Bridges, B. K., Eckel, P. D., Cordova, D. I., \& White, B. P. (2008) Broadening the Leadership Spectrum: Advancing Diversity in the American College Presidency. Washington DC: American Council on Education.

Cahnemann, M. (2003). The Craft, Practice, and Possibility of Poetry in Educational Research. Educational Researcherer, 32, No. 3.

Carnes, M., \& Bland, C. (2007). Viewpoint: A Challenge to Academic Health Centers and the National Institutes of Health to Prevent Unintended Gender Bias in the Selection of Clinical and Translational Science Award Leaders. Academic Medicine, 82, 202-206. https://doi.org/10.1097/ACM.0b013e31802d939f

Carnes, M., Geller, S., Fine, E., Sheridan, J., \& Handelsman, J. (2005). NIH Director's Pioneer Awards: Could the Selection Process Be Biased against Women? Journal of Women's Health, 14, No. 8. https://doi.org/10.1089/jwh.2005.14.684

Chamorro-Premuzic, T., \& Murphy, C. (2017). When Leaders Are Hired for Talent but Fired for Not Fitting In. Harvard Business Review. https://hbr.org/2017/06/when-leaders-are-hired-for-talent-but-fired-for-not-fitting-in

Clunies, J. (2004). Benchmarking Succession Planning and Executive Development in Higher Education. Academic Leadership Journal, 2, No. 4. http://scholarsfhsu.edu/alj/vol2iss4/3

DeZure, D., Shaw, A., \& Rojewski, J. (2014). Cultivating the Next Generation of Academic Leaders: Implications for Administrators and Faculty. Change: The Magazine of Higher Learning. http://fod.msu.edu/sites/default/files/Cultivating\%20the\%20Next\%20Generation\%20of \%20Academic\%20Leaders.pdf

Edwards, R., \& Weller, S. (2012). Shifting Analytic Ontology: Using I-Poems in Qualitative Longitudinal Research. Qualitative Research, 12, No. 2. https://doi.org/10.1177/1468794111422040

Fletcher, J. K. (2001). Disappearing Acts: Gender, Power, and Relational Practice at Work. Cambridge, MA: MIT Press.

Foust-Cummings, H., Dinolfo, S., \& Kohler, J. (2011). Sponsoring Women to Success. http://www.catalyst.org/system/files/sponsoring_women_to_success.pdf

Friedman, T. (2016). Thank You for Being Late, an Optimists Guide to Thriving in the Age of Accelerations (pp. 257-262). New York, NY: Farrar, Straus, Giroux.

Gigliotti, R. A., \& Ruben, B. D. (2017). Preparing Higher Education Leaders: A Conceptual, Strategic, and Operational Approach. Journal of Leadership Education, 16.

Glesne, C. (1997). That Rare Feeling: Re-Presenting Research through Poetic Transcription. Qualitative Inquiry, 3, 202-220.

Gmelch, W. H. (2000). Leadership Succession: How New Deans Take Charge and Learn the Job. The Journal of Leadership Studies, 7, 68-87.

Gmelch, W. H., Roberts, D., Ward, K., \& Hirsch, S. (2017). A Retrospective View of Department Chairs: Lessons Learned. The Department Chair, 28, 1-4. 
https://doi.org/10.1002/dch.30140

Gonzalez, C. (2010). Leadership, Diversity and Succession Planning in Academia. Center for Studies in Higher Education. http://escholarship.org/uc/item/594483fq

Harvard Institute for Educational Management. https://www.gse.harvard.edu/ppe/program/institute-educational-management-iem

Hewlett, S. A., Marshall, M., \& Sherbin, L. (2011). The Relationship You Need to Get Right: How to Be an Effective Sponsor-And a Good Protégé-Throughout Your Career. Harvard Business Review. https://hbr.org/2011/10/the-relationship-you-need-to-get-right

Hewlett, S. A., Peraino, K., Sherbin, L., \& Sumberg, K. (2011). The Sponsor Effect: Breaking Through the Last Glass Ceiling. Brighton, MA: Harvard Business Review Publishing.

Hoehn, A. R., Robbert, A. A., \& Harrell, M. C. (2011). Succession Management for Senior Military Positions. Santa Monica, CA: Rand Corporation.

https://www.rand.org/pubs/monographs/MG1081.html

Korn Ferry Institute (2015). Succession Matters: Effective Succession Planning. https://www.kornferry.com/institute/succession-matters-effective-succession-manage ment-planning?popular

Korn-Ferry Institute (2018). A Critical Roadblock to Diversity. Korn-Ferry Reports and Insights. https://www.kornferry.com/institute/diversity-obstacles-corporate

Livingston, R., Rosette, A. S., \& Washington, E. F. (2012). Can an Agentic Black Woman Get Ahead? The Impact of Race and Interpersonal Dominance on Perceptions of Female Leaders. Psychological Science, 23, 354-358.

Magrane, D., \& Morahan, P. S. (2016). Fortifying the Pipeline to Leadership: The International Center for Executive Leadership in Academics at Drexel. In R. Heller, C. Mavriplis, \& P. Sabila (Eds.), Forward to Professorship in STEM: Inclusive Faculty Development Strategies that Work (pp. 319-336). London, San Diego, Waltham, Oxford: Academic Press.

Markus, H. R., \& Conner, A. (2013). Clash! How to Thrive in a Multicultural World. New York, NY: Hudson Street Press.

Morahan, P. S., Gleason, K. A., Richman, R. C., Dannels, S. A., \& McDade, S. A. (2010). Advancing Women Faculty to Senior Leadership in U.S. Academic Health Centers: Fifteen Years of History in the Making. Journal about Women in Higher Education, 3, 137-162.

Morahan, P. S., Rosen, S. E., Richman, R. C., \& Gleason, K. A. (2011). The Leadership Continuum: A Framework for Organizational and Individual Assessment Relative to the Advancement of Women Physicians and Scientists. Journal of Women's Health, 20, 387-396. https://doi.org/10.1089/jwh.2010.2055

Patton, E. W., Griffith, K. A., Jones, R. D., Stewart, A., Ubel, P. A., \& Jagsi, R. (2017). Differences in Mentor-Mentee Sponsorship in Male vs. Female Recipients of National Institutes of Health Grants. JAMA Internal Medicine, 177, 580-582.

https://doi.org/10.1001/jamainternmed.2016.9391

Rayburn, W., Grigsby, K., \& Brubaker, L. (2016). The Strategic Value of Succession Planning for Department Chairs. Academic Medicine, 91, 456-468. https://doi.org/10.1097/ACM.0000000000000990

Ross, H. J. (2014). Ch. 8 Incubators of Consciousness: Creating More Conscious Organizations. In H. J. Ross (Ed.), Everyday Bias (pp. 127-128). Rowman and Littlefield Lanham MD. 
Rothwell, W. (2005). Effective Succession Planning; Ensuring Leadership Continuity and Building Talent from Within. New York, NY: American Management Corporation.

Travis, E. L. (2013). Sponsorship: A Talent Management Imperative for Science. Washington DC: Association for Women in Science.

http://c.ymcdn.com/sites/awis.site-ym.com/resource/resmgr/Magazine_Article/Sponso rship.pdf https://doi.org/10.1097/ACM.0b013e3182a35456

White, J. S. (2012). HERS Institutes: Curriculum for Advancing Women Leaders in Higher Education. Advances in Developing Human Resources, 14, 11-27. https://doi.org/10.1177/1523422311429732 